\title{
Japon Ruhunda Bahçe Yaratmak
}

\author{
H. Sanem ÇINAR ALTINÇEKIÇ \\ Peyzaj Mimarlığı Bölümü, Orman Fakültesi, İstanbul. \\ Peyzaj Planlama ve Tasarım Anabilim Dalı, Bahçeköy-Sarıyer/İstanbul \\ Sorumlu yazar: saneme@istanbul.edu.tr
}

Geliş Tarihi: 17.06.2016

Özet

Ulusların kendi kültürlerini yansıttıkları birçok öğeden biri de bahçeleridir. Bu bağlamda, bahçelerine bakarak bir milletin tabiatı nasıl kabullendiğini veya onu nasıl fethettiğini ve yorumladığını anlamak mümkündür.

Japonya, milli ve dini değerlerini koruyarak, kendine has sosyal ve kültürel yapısı ile gelişmiş ülkeler arasında en ön saflarda yer almaktadır. Japon sanatlarının güzelliği, duyurulmak için değill, yaşanmak ve paylaşılmak içindir. Japon bahçesi yaratmadaki temel ilke, kendi ruhundaki duygu ve güzellikleri doğanın eşsiz güzellikleri ile bütünleştirip bahçeye uyarlama fikridir. Bu fikir ile Japon bahçe kültürü günümüzde de ayrı bir öneme sahiptir. Japon bahçe kültürünü daha iyi algılayabilmek için tasarım prensiplerini ve onun ruhunu iyi kavramak gerekmektedir.

Anahtar Kelimeler: Japon ruhu, Japon kültürü, Bahçe prensipleri.

\section{Abstract}

Garden Design in Japanese Spirit

One of the many elements that nations reflect their characteristics are gardens. In this context, by looking at their gardens, it is possible to comprehend how a nation accepts or conquers and interprets the nature.

Japan is among, if not the most, developed countries while preserving its national and religious values as well as its unique social and cultural structure. Beauty of the Japanese arts is not to be announced, but to be lived and shared. The basic principle in creating a Japanese garden is to harmonize sensations and beauties of one's own soul with unique beauties of nature and adapt them to a garden. With this idea Japanese garden culture has a distinctive importance today. It is necessary to truly comprehend its design principles and the Japanese spirit itself in order to recognize the Japanese garden culture in a better way.

Keywords: Japanese spirit, Japanese culture, Garden principles

\section{Giriş}

Bat1 Dünyası'nda kültür, güzel sanatlar, edebiyat, felsefe gibi beşeri (manevi) değerler karşılığında kullanırken, Japonlar için, insanın öğrenebileceği her şey kültürdür (Güvenç, 1995). Bugün "Japon Kültürü” nün temeli Muromaçhi (1336-1573) Döneminde atılmıştır. Bu dönem, Japon sanatlarının "Zen Dönemi” olmuştur. Japonların doğaya duyarlılığ1 Zen felsefesiyle birleşerek, dönemin sanat ve kültür hayatına ruh vermiştir. Japon kültüründe her zaman doğrudan anlatım yerine dolaylı anlatım egemen olmuştur. Yaşantıların, duyguların sanat ve kültür düzeyine çıkarılarak, Japon ruhunu yansıtması ile oluşan kültürel yapı, kendisini diğer kültürlerden farklı kılmaktadır (Çınar ve Öznam, 2010). Ulusların kendi kültürlerini yansıttıkları birçok öğeden biri olan bahçeler, mekânsal kullanım ve doğa ilişkisi, toplumsal kültürün, mimari ve sanatsal birikiminin önemli bir ürünüdür. $\mathrm{Bu}$ bağlamda, bahçelerine bakarak bir milletin tabiatı nasıl kabullendiğini veya onu nasıl fethettiğini ve yorumladığını anlamak mümkündür. Japonların Budizm ile tanışmasının ardından Japon kültürü de önem kazanmaya ve yaşamı şekillendirmeye başlamıştır. En temel haliyle sadelik, netlik değerlerinin hakim olduğu, evrendeki her şeyin bir ruha sahip olduğunu kabul eden Japon kültürü, diğer tüm dünya ülkelerinin bahçeleri içerisinde en önemli, en gizemli tek Asya ülkesidir.

\section{Japon Ruhu ve Bahçesi}

Japon bahçesi, hiçbir zaman Avrupa'da olduğu gibi zenginlik ve lüks maddesi olarak düşünülmemiş, daha çok Japon halkının öz karakterinde mevcut tabiat sevgisinin ve özleminin bir parçası olarak kabul edilmiştir (Çınar ve Öznam, 2010). Güvenç'e (1995) 
göre; Japon bahçesi, günlük hayattan, uygarlıktan bir kaçış değil, geçmişle bir buluşma yeridir. İnsan eli değmemiş gibi duran Japon bahçesinde aslında el değmemiş yer yoktur. Japonların göllere, dağlara, nehirlere, kayalara ve ağaçlara karşı duydukları sevgi, doğaya olan hayranlıklarının bir kanıtıdır. Doğayı küçülmüş olarak yeniden tasarlamak ve kendi ruhundaki duygu ve güzellikleri de katarak doğayı bahçeye yeniden uyarlamak, Japon bahçe sanatının temel ilkesidir (Frederic, 1972). Biçim, renk ve duygu bütünlüğü, Japon sanatının estetiği'dir. Duygusal bütünlük, gözün gördüğü aklın kavradığı, durağan, değişmez, kusursuz bir güzellik değil; duygunun tanıdığı doğal bir gizem, bir büyüdür (Güvenç, 1979). Hiçbir sanat eserinin, izleyici tarafından, sanatçının niyetine eş olarak yorumlaması gerekmez. İzleyici, eseri kendi inançları ve duyguları doğrultusunda yorumlar. Burada önemli olan, izleyicinin kafasında oluşan düşünceler ve duygulardır (Keskin ve Seyrek 2008). Japon bahçesinin tasarımında Taoist felsefenin karşıtlıklar ilkesi etkili olmuştur. Bu ilke Yin (pozitif) ve Yang (negatif) kelimeleri ile ifade edilir. Bahçede pozitif, erkek öğeler, tüm tür ve biçimleri ile bitkilerdir. Negatif dişi öğeler, çeşitli biçimleri ve boyutları ile kayalardır. Bitki ve kayanın tasarımında denge oluşturulması bu inanıştan kaynaklanmaktadır (Engel, 1965). Bahçe, kişinin duygularının ve kalbinin istediklerini görebilmesi amacı ile tasarlanır. Bahçenin bütün bu bahsedilen tasarım amaçları dışında en önemli ve son amac1, bahçeyi konutla bir bütün olarak algılayıp doğanın mükemmel ve övgüye değer bir parçası yapmaktır (Frederic, 1972). Japon mimarlığ 1 , minimalizm ve basitlik, teknik mükemmellik ve ustalıkla birleştirilmiş malzeme kullanımı ve asimetrik biçimler olarak özetlenebilir. $\mathrm{Bu}$ özellikler Japon kültürel kimliğine dayanan Japon estetiğini oluşturan özelliklerdir (Edlinger, 2008).

\section{Japon Bahçesi Yaratma Stilleri}

Stil ne olursa olsun ana fikir, sürprizler, duygu bütünlügü̈, göz alıc1 ve hayali canlandırma, doğal bir atmosfere dayandırılmasıdır. Japon bahçeleri üç stilde tasarlanmaktadır.
Sansui Stili: Bu stil, göletler, çağlayanlar, köprüler ve adalar gibi peyzajın elemanları ile tepecikler üzerinde odaklanmaktadır. Aslında bu tepecik formları, su öğesi ve bitkilendirmeye fon oluşturur (Şekil 1) (Davidson, 1983). Bu stilin vazgeçilmez eleman1 sudur.

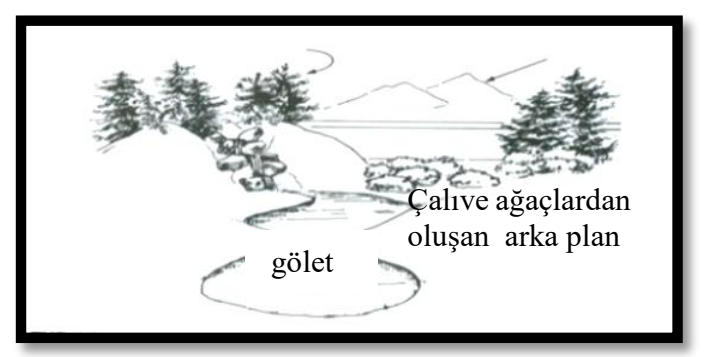

Şekil 1. Sansui stili (Davidson, 1983)

Kare-Sansui Stili : Daha çok "kuru manzara bahçesi" olarak bilinir. Öğeler temel olarak Sansui stiliyle benzerdir, ancak bu stilde en önemli unsur, suyun tasvir edilmesidir. Susuz bölgelerde, su etkisi yaratmanın formülü çakıl, küçük taşlar, kum ya da kırık taş parçaları ile olmaktadır (Şekil 2). Suyun hareketinden kaynaklanan dalgacık ve girdapları yaratmak istenirse tırmıkla şekil verilir. Ada ve köprü gibi öğelerde, su varmış gibi planlanır (Davidson, 1983).

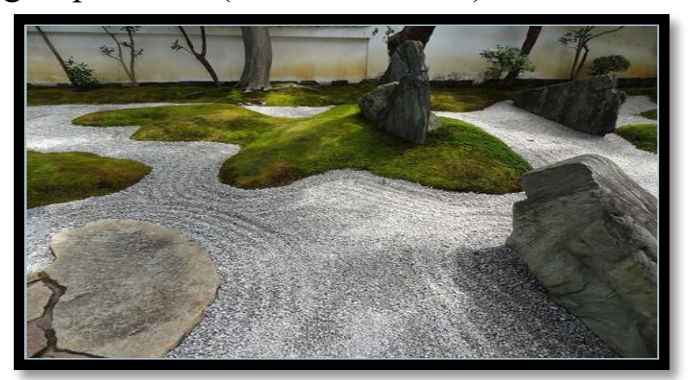

Şekil 2. Kare-sansui stili (Ergan, 2013)

Shakkei (Ödünç Manzara) Stili: Bu stil, uzak bir manzaranın bahçe kompozisyonuna dahil edilme yöntemidir. Bir göl, okyanus, ormanlar, büyük ağaçlar ve hatta bir mimari yap1 bile "shakkei"yi yaratabilir (URL 1, 2013). Japon bahçeleri, su içersin ya da içermesin, ödünç manzara tekniği ile yapılmalıdır. Tasarım dikkatli bir şekilde bu manzara etrafinda şekillendirilmelidir. Bahçenin belli bir kısmında ya da tamamıyla bahçe içerisinde mevcut bir manzara varsa, bu özellik dikkatli bir bitkilendirmeyle mevcut bahçe özelliklerinin önünde, arkasında veya 
arasında görülmesine izin verilecek șekilde tasarıma dahil edilebilir. Bu stilde, bahçenin dışındaki doğal manzaranın, görsel alanın içine alınması, tekniğin etkisini arttırmak amaciyla, dikey çerçeveleme kullanılarak yapılır (Özgen, 1988) (Şekil 3). Bu teknik ile bahçe olduğundan daha büyük bir görünüme sahip olur.

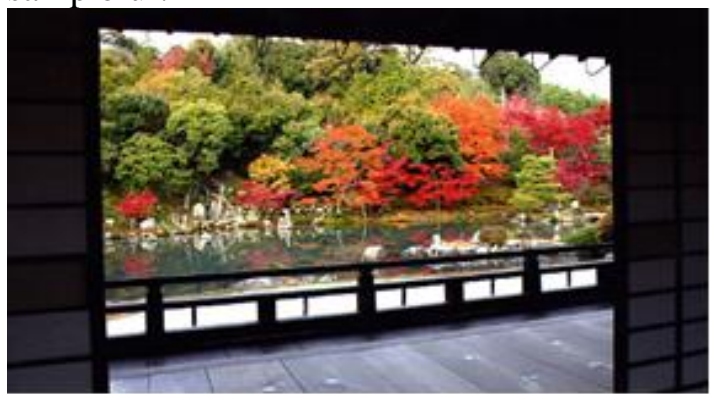

Şekil 3. Shakkei Stili (Ergan,2013)

\section{Japon Ruhunu Yansitan Ögeler}

Su: Japon manevi hayatının merkezinde arınma aracı olarak yer alır. Su, bahçe içinde hiç değişmeyen ve hep var olan bir öğe olmuştur. Nitekim suyun olmadığı karesansui bahçelerinde bile su, taşlarla ve çakıllarla ifade edilir. Su kullanımında amaç ortama huzur, serinlik ve canlılık kazandırmaktır. Su, en çok tepe bahçelerinde önem kazanmıştır. Bu tip bahçelerde kayalar, tepeler ve su büyük bir denge ve incelikle işlenmiş ve eşsiz manzaralar ortaya çıkarmıştır (Conder, 1964). Budizm inancına göre dağlardan çıkarak göle veya denize akan su, insanın doğumu ile ölümü arasındaki yaşamı temsil etmektedir. Suyun içerisinden akıp geçtiği kayalar ise hayattaki zorluklar olarak kabul edilir (Keane, 1996).

Göletler: Genellikle bahçenin kalbi olarak düşünülür. $\mathrm{Bu}$ etkiyi aksettirmek için genellikle kalp formuna benzer şekilde tasarlanır. Gölet planlanırken üç önemli nokta akılda tutulmalıdır (Davidson, 1983): İlki, gölet, mekanın odak noktasını oluşturur. Fakat bulunduğu mekanın merkezinde olmak zorunda değildir. Bahçenin geriye kalan kısmı göletin etrafında tasarlanmalıdır. Bahçe tasarımlarında, suyun tepecikten araziye düştüğü nokta, odak noktasıdır ve arkadaki tepeleri vurgulamalıdır (Şekil 4). İkinci önemli nokta, gölet ve çevresinde simetriden kaçınılmasıdır. Düzenli ve simetrik formlar yapaylık katacağından Japon bahçesinin sahip olması gereken doğallık hissini azaltacaktır.

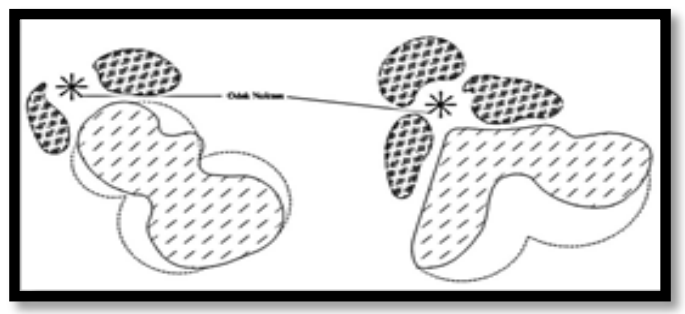

Şekil 4. Odak noktası yaratılan göletler

Üçüncüsü ise, göletin şekli, dikkatli bir bitkilendirme ile birkaç farklı görüş açısına olanak sağlayacak şekilde tasarlanmalı ve farklı görünümler sunmalıdır (Şekil 5) (Davidson, 1983).

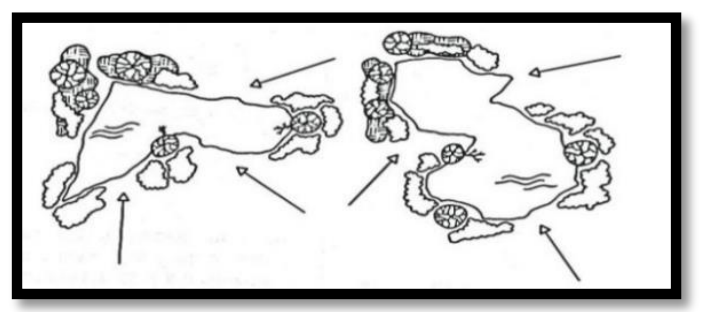

Șekil 5. Spesifik görüș hatlarının yaratılması (Davidson, 1983)

Göletlerde suyun yüzeyde küçük dalgalanmalar-hareler- yapması için dipten su yüzeyi düzlemine kadar uzanan kayalar yerleştirilir. Böylece deniz ve dalgalar sembolize edilir (Özgen, 1988/2).

Cağlayanlar: Bahçede boyutu ne olursa olsun, çağlayanın sesi ve hareketi bahçeye canlılık getirecektir. Japonlar, doğadaki çağlayan formlarını inceleyerek tek seferde düşen ve kırılarak düșen çağlayanlar olarak iki kategori tanımlamışlardır (Davidson, 1983). Çağlayanların tasarımında da bazı ilkeler vardır. Bu ilkelere göre ana kaskat yüksekte ve genişlik açısından dardır. Yardımcı kaskat ise daha alçak ama daha geniştir. Ana kaskat "yang (erkek)", yardımc1 kaskat "yin (dişi)" olarak bilinir. Bahçedeki manzaranın kasvetli ve derin bir görünüm vermesi için çağlayanın çevresi yoğun bir şekilde bitkilendirilir (Demirbaş, 1997). Geleneksel Japon bahçelerinde Shingon Budizmine göre çağlayanlar, Budist tanrısı olarak kabul edilmiştir Bahçenin köşesinde tasarlanan çağlayanların, bahçenin merkezine yerleştirilmemesinin nedeni, daha doğal manzara elde etmek ve akan suyun arkasındaki dağları hissettirmektir. Çağlayanın kenarlarında bulunan kayalar 
suyun aşağı doğru akmasını sağlarlar. Bu kayaların konumlandırılırken doğal olmasına önem verilmelidir (Masuno, 2003).

Akarsular: Akarsuların eğimleri genellikle $\% 3$ civarında olup, akış hızı akarsu tasarımında oluşturulan kıyılara göre değişim göstermektedir (Seike vd.,1992). Akarsular akış yönü ve hızı bakımından 3 bölüme ayrılmaktadır. Akarsuyun başlangıç noktası "hayase", hafifçe eğimli orta kısmı "churyu" ve k1vrilarak akan durgun kisım ise "karyu" olarak bilinir. Geometrik şekillere sahip olan bu kayalara çarpan suyun yön değiştirmesi amaçlanmaktadır. Akarsuların kıvrımları orta kısımda azalmakta olup suyun akışı daha da yavaşlamaktadır (Masuno, 2003).

Adalar: Adalar göletler için mükemmel odak noktasıdır. Ölçek ne olursa olsun boyut kazandırır ve derinlik hissi verirler. Sembolik amaçlı kullanılan adalar, çoğunlukla bahçenin merkezinde tasarlanmakla birlikte, okyanus ortasında yer alan adaları temsil etmektedir. "Nakajima" adiyla bilinen bu adalar, gerçekleşmesi imkansız üç efsanevi düşünce adası olarak Horai dağı, Turna kuşu ve Su kaplumbağası adasını temsil etmektedir. $\mathrm{Bu}$ adalar Taoist düşünceye göre; uzun ömürlülüğün sembolü "Ölümsüzlük Adası" olarak kabul edilir (Masuno, 2003).

Turna kuşu adasının tasarımında düşey pozisyonda ve keskin kenarlı kayalar kullanılır (Şekil 6). Bu ada, Himalayalar'daki keskin, sarp kayalıklardan oluşan dağları simgeler (Slawson, 1991). Turna kuşu adasında kanat taşı en büyük ve en önemli taştır (Davidson, 1983).

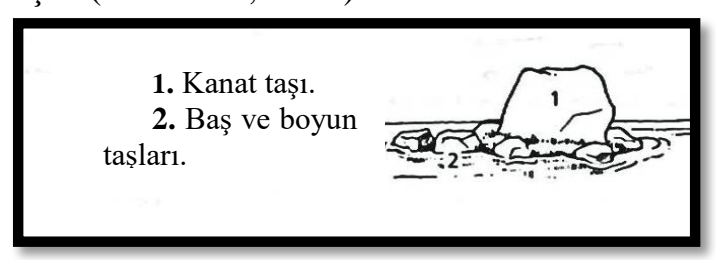

Şekil.6 Turna kuşu adası (Davidson, 1983)

Kaplumbağa adası için ise baş taşı önemlidir. Boyun, bacak gibi yerleştirilen daha küçük dört taşa dayanır. Biri hafifçe yukarı dönük kuyruk, biri de yavru kaplumbağayı sembolize eder şekilde üsttedir (Şekil 7). Bu adalar, özellikle yeni odak noktaları yaratmak için geniş göletlerde uygundur.

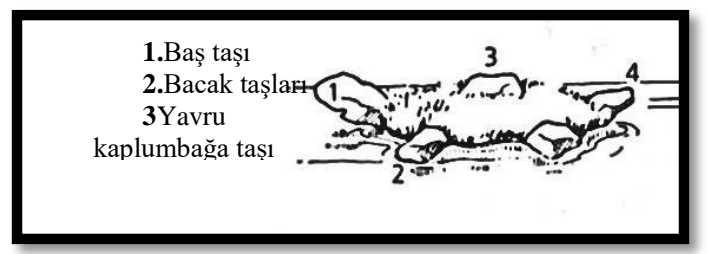

Şekil 7. Kaplumbağa adası (Davidson,1983)

Belirtilen iki temel şekilden sonra, adaların diğer tipleri tek veya küçük kaya gruplarıdır. Bunun yanında toprakla kaplanmış, küçük bir ağaç veya çalıların bulunduğu ya da her ikisininde kombinasyonu şeklinde bitkilendirilmiş kayalardan oluşan adalar en uygun görüntüleri oluşturur (Davidson, 1983). Küçük göletlerde, su yüzeyinin üzerinde ada yaratmak için tek bir kaya yeterlidir. Büyük yassı bir kaya ile büyük bir ada etkisi yaratılabilir. Adalar, daha büyük göletlerde üzeri bitkilendirilmiş ve toprakla doldurulmuş birkaç kayadan oluşabilir, böylelikle gölete derinlik ve detay kazandırılmış olur (Davidson, 1983). Tasarıma ilginçlik katmak için adaya köprü konulabilir. Adanın baskın olmaması ve gerekli görüş açılarını kapatmaması için dikkatli olunmalıdır (Şekil 8).

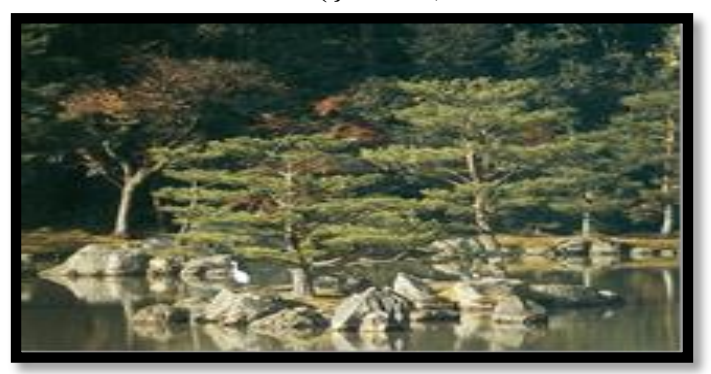

Şekil 8. Ada görünümü (Nitschke, 2003).

Adalar, dikkatleri göletin çeşitli kısımlarına yönlendirerek yeni görüş açıları yaratmak için kullanılabilir. Kural olarak adalar, tasarımın tamamlayıcı bir parçası olarak düşünülmeli, tasarıma sonradan eklenmemelidir.

Köprüler: Köprülerin Budizm dinine göre farklı anlamlar taşıdığı bilinmektedir. Heian dönemi bahçelerinde, gölün ortasındaki adalara ulaşmak için kullanılan köprüler, yeryüzündeki insanın cennete ulaşmak için Tanrıyla olan bağlantısını temsil etmektedir (Keane, 1996). Kamakura döneminden sonra görsel amaçlı tasarlanan köprülerin çoğu ise taştan yapılmıştır. Bu bahçelerde köprüler, 
manzara ve duyguların simgeleri olarak kabul edilmektedir (Masuno, 2003). Günlük yaşamda insanların bir dere veya akarsuda karşıdan karşıya geçmelerini sağlamak, alternatif bakış açıları oluşturmak, adaya ulaşmak ya da bir adayı diğerine bağlamak gibi birkaç fonksiyona sahiptir (Seike vd., 1992). S1kça görülen köprüler, ay görünümlü köprüler ve zigzag köprülerdir. Çoğunlukla taş veya ahşaptan yapılan ay formundaki köprüler, uçlara doğru incelmesi ile karşıya geçmek tehlikeli olduğundan genellikle kenarlarında korkuluklara yer verilmiştir (Şekil 9). Zigzag köprü tipi, daha çok Edo dönemindeki gezinti bahçelerinde kullanılmıştır (Şekil 10).

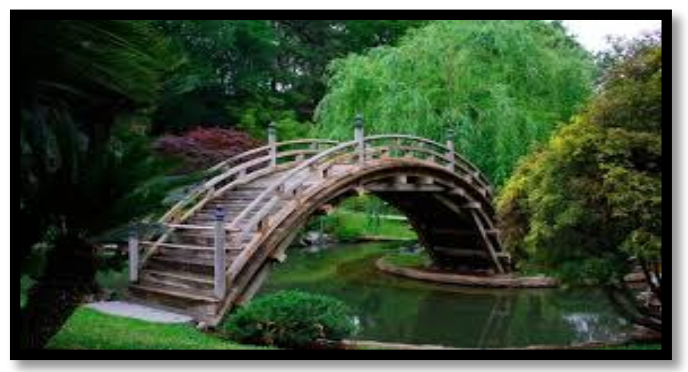

Şekil 9. Ay görünümlü köprü (URL2,2015 )

Çoğunlukla bahçelerde, sığ göller veya bataklıklar üzerinde tasarlanırlar. Ayrıca bir efsaneye göre, kötü niyetli ruhlar bu zigzag köprülerden geçemezler (Ketchell, 2001). Köprü eğer bir tapınak bahçesi içerisinde bulunuyorsa kırmızı renge boyanır, ancak bunun dışındaki diğer Japon bahçelerindeki köprüler boyanmazlar.

Kaya ve Kaya Grupları: Birçok kültürde taş varoluşun, bağlılı̆̆ın, dayanıklılığın simgesidir (Ben-Joseph, 1987).

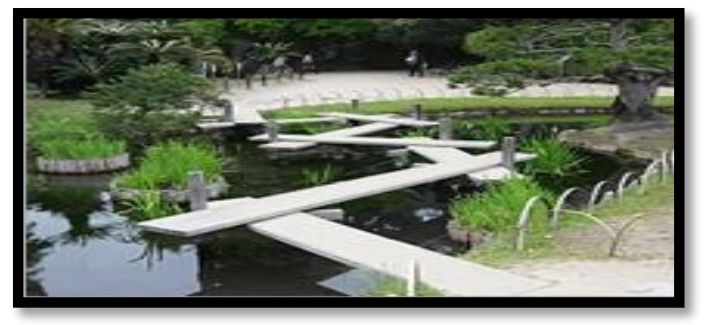

Şekil 10. Zigzag köprü (Ergan, 2013)

Japon bahçe sanatının vazgeçilmez elemanı olan kayalar, tasarımların iskeletini oluşturmaktadır. Sansui ve Kare-sansui bahçelerinde fonksiyonel, estetik ve sembolik amaçlı kullanılan kayalar, çoğunlukla çakıllarla birlikte tasarlanmaktadır (Seike vd., 1992). Budizmde, kayanın bir Tanrının ruhunu taşıdığına ya da doğaüstü bir özelliğe sahip olduğuna inanılmaktadır.

Nara ve Heian dönemlerinde etkili olan geomantik düşünceye göre kayaların şekli ve rengi sahip oldukları güce göre farklılıklar göstermektedir. $\mathrm{Bu}$ dönemdeki kayalar güçlerine göre adlandırılmışlardır. Tabu kayası, Ejderhanın evi kayası, Kralın ruhu kayası vb. buna örnek verilebilir (Keane, 1996). Kayalar yerleştirilirken dikkat edilmesi gereken noktalar vardır. Bunlardan ilki, toplam sayıları tek sayı olmalıdır (Tonder vd., 2005). Bunun nedeni Çinliler ve Japonların tek sayıları uğurlu saymalarıdır (Çınar ve Atakan, 2008). Özellikle üçlü gruplar halinde kullanılması, Hristiyanlardaki gibi üç sayısının dinsel bir öneminin olmasıdır. 5 ve 7 de kullanılan diğer önemli sayılardır. Yedi taşın kullanıldığı bahçelerde ise çoğunlukla 32-2 ya da 2-3-2 taş dizilimleri tercih edilmektedir (Seike vd., 1992). İkinci nokta ise, standart kaya şekillerinin betimlenmesidir. Eski Japon bahçıvanlar, dört temel kaya şekli belirlemişlerdir: uzun ve ince, kısa, yay şeklinde, yassı ve düz (Şekil 11). (Bu isimler, koşan köpekler, annesini takip eden balina ve hatta kaplan yavruları gibi kayaların daha şiirsel tanımlamalarından gelmektedir) (Davidson, 1983). Japon bahçelerinde önemli noktalardan biri de, bahçeye bakan insanların, kayaları gerçekte olduğundan daha büyük görmelerini sağlamaktır. Bu amaçla kayaların alt kısmı toprak yüzeyinin altındaymış gibi gösterilmektedir (Masuno, 2003). Bir başka önemli nokta ise, kayaların önceden beri bahçedeymiş izlenimi yaratmalarını sağlamaktır. $\mathrm{Bu}$ nedenle tasarımlarda genellikle hava şartlarından dolayı aşınmış, üzeri yosun ve mantarla kaplı kayalar tercih edilir (Seike vd., 1992). Bahçelerde genellikle düz ve yuvarlak formdaki tortul kayalar (suisei-gan); göl kenarlarında ve adım taşlarında, volkanik kayalar (kasei-gan); pürüzlü yapıları ile bahçede adım taşı ya da sembolik amaçlı tasarlanan dağların zirvelerinde kullanılmaktadır. Sert bir yapıya sahip olan metamorfik kayalar (hansei-gan) ise: çağlayan ve akarsu kenarlarında kullanılmaktadır (Young vd, 2005). Kaya düzenlemelerinde en önemli husus, dengedir. 
Denge, merkez taş grubu oluşturularak sağlanmaktadır. Merkez taş grubu, uzun-ince, kısa-bodur, düz-yassı ve yay şeklinde tamamlayıcı taşlardan oluşmaktadır. Birinci taş uzun-ince olup, ikincisi ise kısa-bodur taştır. Alçak ve düz taş ise, bu ikili grubun önünde ve merkez taş grubuna denge sağlayan taştır (Şekil 11). Burada gösterilen sıra, grubun sistematik olarak nasıl yapıldığının bir örneğidir. Grubun yanlarına eklenen taşlar ise gruba hacim kazandırılır (Şekil 12), (Davidson, 1983). Kaya kompozisyonlarında kayaların sahip olduğu potansiyel gücün, kayanın eğimli olduğu yöne doğru aktarılacağı düşünülür ve genellikle kayalar sola doğru uzayan formlarda tasarlanırlar. Kayaların tasarımında amaç; doğadaki pozisyonları ve şekilsel manzara bütünlüklerinin kullanıldığı şekilde bahçeye yansitmaktır (Ketchell, 2001). Kaya kompozisyonlarında kayaların şekli, yönü, boyutları ve birbirine olan uzaklıkları önemli rol oynar. Kaya kompozisyonlarında dikkat edilmesi gereken hususlar şunlardır (Çınar ve Atakan 2008): Aynı ölçüdeki kayalar kullanılmamalı, aynı doğrultuda olmamalı, Kayaların da birer canlı olduğu düşünülüp hissettirilmelidir. Bahçelerde gerçek ruhu bozacak taşlardan kaçınmak gerekir. $\mathrm{Bu}$ taşlar; Hasta taş; biçimsiz, eğri taş, Ölü Taş; horizontal olarak kullanılan, ölü bir vücut sergileyen taş, Yoksul Taş; diğer taşlarla grup oluştururken dengeyi bozan taş şeklinde gruplandırılabilir (Anonim,2003).

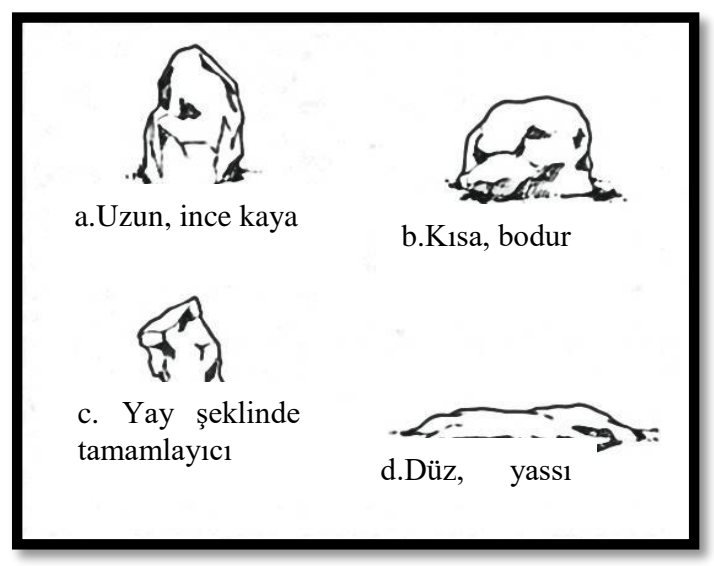

Şekil 11. Temel kaya şekli (Davidson, 1983)

Kayalar yerleştirilirken yatay, köşegen, dikey şekiller ile cennet, dünya ve insan üçlemesinin eş değerde olduğu göz önünde bulundurulmalıdır (Çınar ve Atakan, 2008).

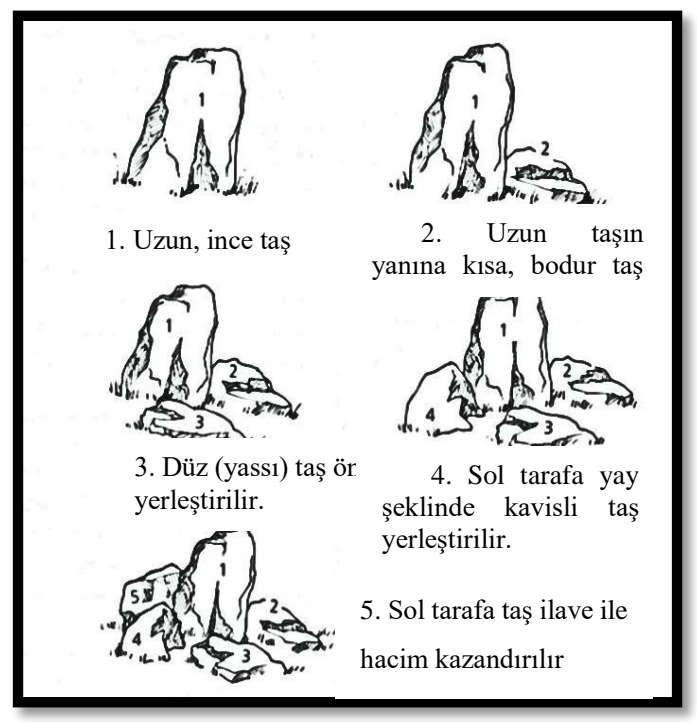

Şekil 12. Merkez taş grubu ( Çınar ve Atakan 2008)

Yollar: Yollar, devamlı ya da kesikli (adım taşları) şekillerde olabilir. Hangi malzemenin kullanılacağı materyalin bulunabilirliği, kullanılabilirliğine ve kişisel zevklere bağlıdır. Adım taşları ile oluşturulan yollar, bahçe sınırları dışındaki yaşamla tezat oluşturacak bir atmosfer yaratmaya yardım eden, düzensiz, kesik ve informal şekilleriyle daha çok çay bahçelerinde kullanılırlar. Sirkülasyonların düzenlenmesinde eve giden yol ile bahçede gezinti amaçlı yollar arasında mutlaka fark olmalıdır. Eve giden yol, ziyaretçinin eve ulaşmasını geciktirmeyecek, sade ve dikkat çekmeyecek bir döşeme ile yapılmalıdır (Davidson, 1983). Adım taşları, çay törenlerine gelen misafirlerin uzun giysilerini (Kimono) ve ayakkabılarını çamurdan korumak ve kaygan yosun üzerindeki yürüyüşlerde oluşabilecek tehlikeleri önlemek amacı ile tasarlanmıştır. Taşların asimetrik dizilimi bahçenin doğallığını ortaya çıkarmaktadır (Seike vd., 1992). Adım taşları, bir adımın rahatça atılabileceği (genellikle $60 \mathrm{~cm}$ ) genişlikte (Ketchell, 2001), $(10 \mathrm{~cm}$.$) aralıklarla dizilir$ (Yoshikawa, 1996). Adım taşlarının yerleşiminde farklı dizilişli gruplar oluşturulmuştur (Şekil 13). 


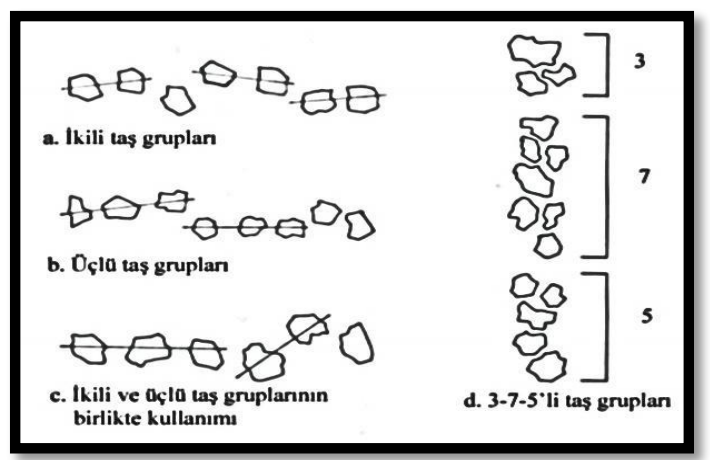

Şekil 13. Sirkülasyonda taş grup kullanımı (Davidson, 1983'tan uyarlanmıştır).

Yol ağının en önemli taşlarından biri olan yol ayrımı taşı Şekil 14'da görülmektedir Kavşaklara (kesişim noktalarına) yerleştirilen bu taş, vurgu yaratmak ve yolların dağıldığ noktada bir çeşit dayanak etkisi yaratması amacıyla çevresindeki taşlardan biraz daha büyüktür (Davidson, 1983).

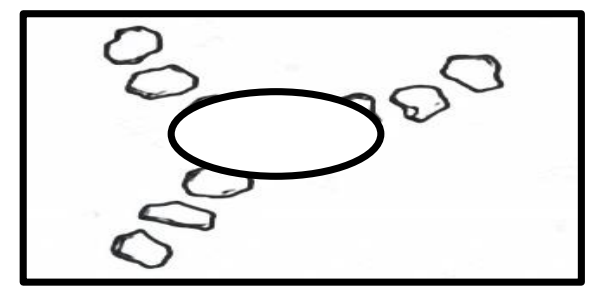

Şekil 14. Taş ayrım taş1 (Ketchell, 2001)

Taşlar tek bir parçaya dönüşüp birbirine uygun döşenmesi yerine, taşların birbirlerine karşı durdukları algısını uyandıracak şekilde (Ketchell, 2001) belli bir açıyla dizilmelidirler. $\mathrm{Bu}$ diziliş daha geniş ve dayanıklılık etkisi verir ve yolu daha geniş ve daha davetkar yapar (Davidson, 1983) Taşlar kesinlikle birbirine paralel olmamalıdır.

Sınırlayıcılar:(çit-duvar-paravan): bahçeyi kuşatmak, bahçe içerisindeki mekanları birbirinden ayırmak gibi amaçlarla kullanılırlar (Keane, 1996). Bahçede sakin bir ortam yaratmak amaciyla sinırlayıcı kullanılmasındaki tek istisnai durum, ödünç alınan manzaranın da bahçeye dahil edilme şeklidir (Şekil 15). Sınırlayıcıların diğer bir fonksiyonu ise, arka fon oluşturarak bahçeyi bölümleyen iç perdelemeler oluşturmaktır.

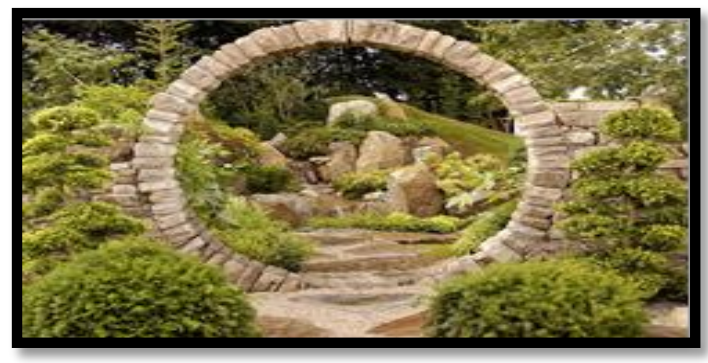

Şekil 15. Ödünç alınan manzara (URL 3, 2013)

Sınırlama amaçlı kullanılan elemanlar, mahremiyet açısından olduğu kadar bahçede sakin bir atmosfer yaratma açısından da önemlidir (Davidson, 1983). Bahçenin bölümlendirilmesinde de çit ve paravan kullanımı da önemlidir. Tamamen ya da kısmi olarak kapalı şekilde yapılabilirler. Bazı bahçelerde bitkiler bu amaç için yeterli olabilir. Bahçede gizli bölümlerin yaratılmasında etkili önemli materyalden biride, bambulardır (Şekil 16). Bambular, Japon bahçelerinin olmazsa olmazıdır. Çünkü düşünceye göre bahçenin tüm detaylarının bir bakışta görülmemesi ve bazı öğelerin gizlenmesi gerekir. Böylece, yaratılan detaylara ve sürprizlerle hayali canlandırma olanağ 1 ortaya çıkacaktır.

Bitkiler: Bitkilendirme olabildiğince doğal olmalıdır. Bitkilendirmede simetriden kesinlikle uzak durulmalı, çok sık dikimden kaçınılmalıdır. Eğer bahçe güzel manzaralara sahipse ya da etrafinda ağaçlar ve çalılar varsa, bunlar olabildiğince bahçedekilerle harmanlanmalı, bitkiler tasarıma arka plan oluşturmalı ve alana uyum sağlamalıdır.

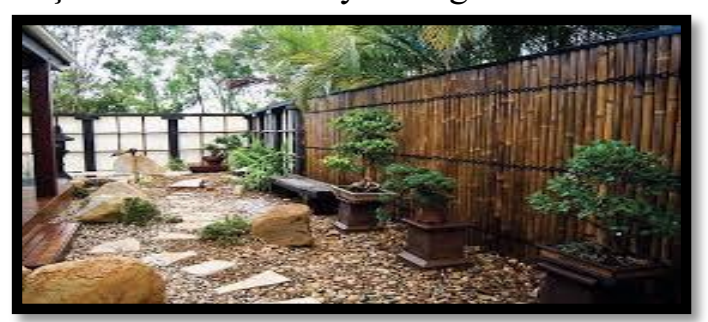

Şekil 16. Bambu sınırlayıcı (Simon, 2014)

Japon bahçelerinde çiçekler çok dikkatli ve nadir kullanılırken, herdemyeşil bitkilere fazlaca yer verilir. Herdemyeşil bitkilerin bahçede huzur verdiği düşünülür (Ketchell, 2001). Yapră̆ını dökenlerden özellikle gövde ve dal güzelliği olan türlere daha çok yer 
verilir. Mevsimlerle yaprak rengini değiştiren bitkiler ayrı bir önem kazanır. Ağaç ve çalılar, bahçe mekanındaki bazı objelerin (köprü, fener, kaskat vb.) kısmen saklanmasina ve daha derin bir mana kazanmalarına imkan verecek şekilde yerleştirilirler. Ağaçların tertibinde genellikle üçlü bir grup ve bir, biriki, beş-iki vb. tertipler kullanılır (Akdoğan, 1974). En çok görülen bitkiler İğne yapraklı türler: Pinus sp. (Çam), hiçbir bahçe çam ağacı olmadan düşünülemez. Çam ağac1, hem erkeklik kudretinin sembolü hem de uzun ömürlülügün ifadesi olarak yer alır (Akdoğan,1974). Herdemyeşil olması, doğanın değişimine karşı sürekliliği temsil eder. Tasarımlarda en çok kullanılan tür, Pinus densiflora (Japon kırmızı çamı) ve Pinus thunbergii (Japon siyah çamı)'dir (Slawson, 1991). Pinus densiflora dişiyi, Pinus thunbergii ise erkeği sembolize eder (Keane, 1996). Pinus mugo, dağları ve deniz kıyısını sembolize eder. Çamın, doğuya dikilmesi çok önemlidir (Slawson, 1991). Pinus parviflora bitkisi ise, sonsuz uzay1 temsil etmek için kullanılmıştır (Hopson, 2007). Yapraklı türler: Acer palmatum (Japon Akçaağacı), tepe, dağ kompozisyonu yaratmak için kullanılan ana bitkilerden biridir. Çevrelendiği alan ile uyumlu ve çekici yerlere dikilmelidir. Dikilmesi gereken ana yönü kuzeydoğudur (Slawson, 1991). Citrus sinensis (Portakal), mutluluk, şans ve zenginliği temsil eder. Ginkgo biloba (Japon mabet ağac1), köklerini tarihin derinliklerine dayamış, ulu bir ağaçtır. Yaprakları başka hiçbir bitkiye benzemez. Yelpazeye ya da bir ördeğin ayağına andırır. Bu bitki Çin ve Japonya'da kutsal ağaç sayılır ve mabetlerin bulunduğu yerlere dikilir. Bitki bakımsızlıktan ölürse bulunduğu mabet de ölmüş sayılır (Pilevleni,2007). Prunus sp., bahçede her mekanda kullanılır. Dikim yönü güneydir (Slawson, 1991). Erik ve kirazlar yok olmanın sembolüdür. Japon bahçelerinin vazgeçilmez bitkisidir. Ortaçağda erik ağacı çiçeklerinin ömrünün kısalığı ve ihtişamı, dönem samuraylarının hayatına benzetilmiştir (Keane, 1996). Erik ağacı çiçeklerinin beyaz rengi ile saflığ ve temizliği sembolize eder (Du Cane, 1908). Erik ağacının (Prunus mume) çiçekleri cezbedici olarak baharı müjdelemektedir (Deitz 2008). Kiraz ağaçları Prunus serrulata 'Kiku Shidare - Sakura',.
Kısa hayatları ve ani ölümleri ile sakuralar, samuray yaşam tarzını benimseyen Japonlar için bir çiçekten çok daha fazla şeyi ifade eder. Japon savaşçıları olan samuraylar, aynı sakuralar gibi yaşamın içinde parlar. Savaşırken, her an ölebileceklerini düşünmektedirler. Yani sakura, Japon toplumu özellikle de samuraylar için felsefi bir özellik taşır. Kiraz çiçekleri, hem hayatın güzelliklerini ve yaşama sevincini hem de hiç umulmadık bir anda ölümün gelebileceğini hatırlatırlar. Çiçekleri ağaçta en güzel göründükleri dönemde solmadan ve kurumadan yere düşmektedirler. Her yıl Nisan ayında çiçeklerinin açması ile ülkede bayram olarak kutlanır. Bir ağacın gölgesinde dikilen kiraz ağac1 yüksek bir dağı veya bahçenin manzarasına giren uzaktaki bir dağ ifade eder Sakura Kiraz Ağac1, sadece bir çiçeğe dönüştüğü an değil, aynı zamanda dökülmeye başladığı an da Japon estetiğinin manifestolarıdır. Ölümü sembolize eden bu doğal değişis, aynı zamanda yeni mevsimin habercisidir (Keskin ve Seyrek 2008). Prunus persica (Şeftali ağac1), daha çok büyük ölçekli bahçeler için alternatif bir bitkidir. Dikim yönü doğudur (Slawson, 1991). Japonya'da şeftali çiçeklerinin açması, bir bayram havası yaratır (Du Cane, 1908). Punica granatum (Nar), büyük meyveleri ve kırmızı çiçekleri ile etkili bir manzara yaratır. Göze batmayan bir noktada çevresindekilerle uyumlu bir şekilde tasarlanmalıdır (Slawson, 1991). Salix spp. (Sögüt), özellikle Salix babylonica türü yaygın olarak kullanılır. Eğer ada yoksa sögüt kullanılmaz. Kullanıldığı zaman adanın kuzeybatısına dikilir. Eğer su öğesinde bir köprü varsa bu noktaya sögüt dikilir. Böylece bahçede büyük ölçekli peyzaj etkisi yaratılmış olur (Slawson, 1991). Calilar: Azalea sp. (Açelya), her ne kadar Belçika'nın ulusal çiçeği olarak bilinse de Japonların elinde bir başka değer kazanmıştır. Kerria japonica (Kanarya gülü), bataklık-göllerin en başta gelen bitkisidir. Diğer bahçe tiplerinde ise sınırlayıcı çit ya da bir noktayı vurgulamak için kullanılır (Slawson, 1991). Rhododenron $s p$ (Ormangülü), sarp kayalıkların arasında gizlenmiş ya da bir gölün yukarı kıyısında dikilir ise çok etkileyici olur (Slawson, 1991).Bambular: Bambusa spp (Bambu), güçlülük ve esneklik ile ilişkilendirilmektedir (Ketchell, 2001). Zen tarikatının 
prensiplerinde boş gövde yapısından dolayı boş kalbi sembolize eder (Keane, 1996). Bu bitkinin dikim yönü kuzeydir (Slawson, 1991). Bambu, düz bir şeklide büyümesi ile, Japonya'da dürüstlügün sembolüdür. Japonlar ayrıca yılbaşında giriş kapılarına birbirine bağlanmış bambular ("kodamatsu") koyarlar ve bunun şans getirdiğine inanırlar (Var, 2005). Sarilicilar: Wisteria floribunda (Mor salkım), çam ile birlikte tasarlanır. Bu bitkiyi ağaçların gölgesinde dikmek etkileyici bir tasarım yaratır. Bataklık-göl bahçesinde suyun üzerine doğru yayılmış Mor salkım çiçek açtığı zaman çok etkileyici olmaktadır (Slawson, 1991). Akdoğan'a göre (1974); Japon ruhunda Çam (Pinus sp.), Erik (Prunus mume), Bambu (Bambusa sp.) "Soğuk Mevsimin Üç Arkadaşı", Şeftali ağacı (Prunus persica) "Ölmezlik", Çam (Pinus sp.) ve Bambu (Bambusa sp.) "Uzun Ömürlülük", Muz ise (Musa sp.) "Verimlilik" olarak özel anlam taşırlar. Lotus (Nilüfer) "saflığı", Orchidaceae (orkide) "masumiyeti", Paeonia (şakayık), tüm çiçeklerin kraliçesi olarak bilinir (Xiaofeng, 2010). Bunun yanında yosun bitkisi, sembolik olarak insanların tepelerde bulunan yeșili hissetmeleri ve kayalarla güzel bir zitlık oluşturması amacıyla tasarlanmaktadır (Masuno 2003).

\section{Yardımcı diğer elemanlar:}

Taş Fenerler: Genellikle tek parça taştan yapılmış sütun ve bu sütunun üzerine konulan, 1şığın yayılacağı kadar delik bulunan ilave bir parçadan ibarettir. İlave parçanın delik kısmında mum yer alır. Sert taşlardan yapılanları işlenme zorluğu nedeniyle pahalı olduğundan, yumuşak taşlardan yapılanları daha çok tercih edilir (Seike vd, 1992). Geleneksel olarak fenerler, tapınaklarda ve anit mezarlarda bulunurdu. Ayrica binaların girişine dizilip, evin etrafını aydınlatırlardı. Daha gösterişli olan fenerler, çay seremonilerinde de kullanılırlard1. Bu fenerler sadece ihtiyaç olduğunda yakılırdı (Şekil 18).

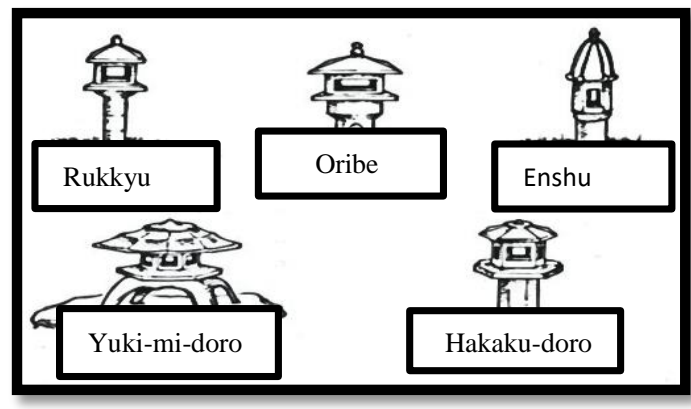

Şekil 18. Fener tipleri (Davidson, 1983'den uyarlanmıştır.)

Bazıları ise ölüm yıldönümleri gibi özel günlerde yanardı. Günümüzde bu işlevleri ortadan kalktığından bahçede aksesuar olarak kullanılmaya başlanmış (Shigemori,1981) olmalarına rağmen, hala önemlerini muhafaza etmektedirler. Bahsedilen tüm işlevlerinin yan1 sıra, büyük, yosun kaplı fenerler, insanların hayatlarının büyük parçası olan sessizlik ve sonsuzluğun simgesidirler. Ayrıca sağlamlık ve devamlılık hissi yaratırlar. Fener tasarımlarının bir kısmı şekilleriyle isimlendirilirler. İnsanların ya da mekanların isimlerini almazlar. Bunların en popülerleri ve en çok Japon kültürünü yansıtan geniş çatılı ve su kenarlarında kullanılan "yuki-mi-doro" (kar izleme feneri) dır (Şekil 18). Genellikle fener etrafina en az iki taş yerleştirilmektedir. Taşlardan biri fenerin önünde durularak fenerin yakılmasına hizmet eder. Diğer taş ise, fenerin yakilması esnasinda mumun üzerine bırakılabilmesi içindir. Bu kombinasyonuna "1şık yakma taşları" adı verilir (Şekil 19). Her ne kadar bugün kullanılmasa da, bu taşlar japon bahçe tasarımının önemli parçası olmuşlardır (Davidson, 1983).

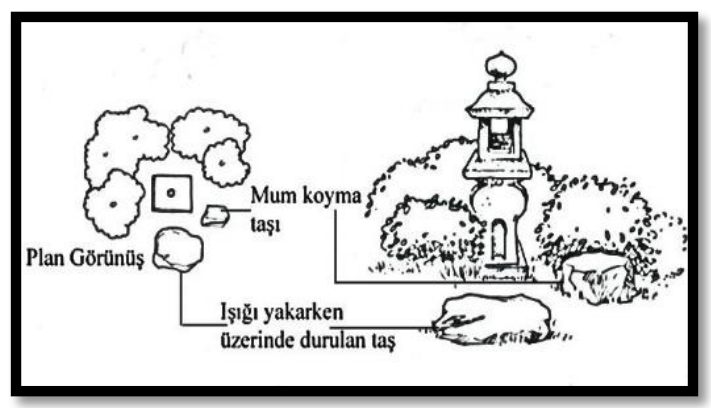

Şekil 19. Işık yakma taşları (Davidson, 1983)

Taş Kule: Hem Budizmin sembolü olan kuleler, 2, 3, 5 ya da daha fazla çatılı 
pagodalara benzerliği ile bilinirler. Tıpkı taş fenerler gibi geniş bir tasarım çeşitliliğine sahiptirler. Japon bahçelerinin ruhunu, doğu kimliğini en iyi yansıtan öğelerden biridirler (Şekil 20). Bahçe içerisinde çok göze batmamalıdır. İdeal olan, ağaç dalları ve yaprakların arasına gizlenmesi ve bu dalların arasından gözükmesidir (Davidson, 1983).

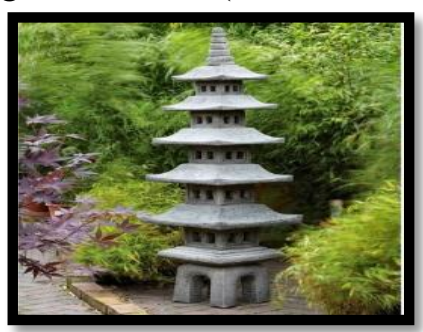

Şekil 20. Taş kule (Çakar,2013)

Su Çanakları: Su çanaklarının kökeni, temizliğe dayanmaktadır. Bundan dolayı, su çanakları, ibadet eden kimselerin, ibadethaneye, seremoniye girmeden önce, ellerini yıkamaları ve ağızlarını çalkalamaları için tapınakların ve çay evlerinin önlerinde bulunurlardı ( Şekil 21), (Şekil 22). Çanaklar genellikle taştan yapılır ve derin bir anlam içerir. Anlamı; ziyaretçi çanağı kullanmak için eğilmek zorunda olduğu için seremoniye katılmadan önce zihninde "saygı" düşüncesi uyanıyor olmasıdır. Böylece kişi saygı ile kibrinden arınacaktır (Davidson, 1983).

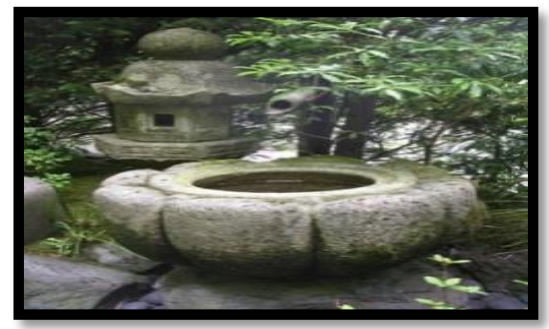

Şekil 21. Su Çană̆ (URL4, 2015)

Su çanaklarının da etraflarında bir grup taş bulunmaktadır. Bu taşlar su doldurmak veya el yıkamak için kullanılırlar (Engel, 1969).

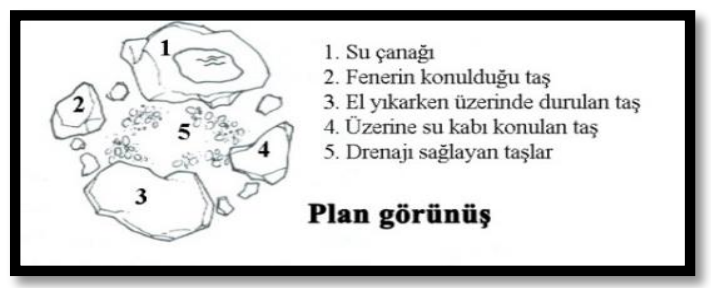

Şekil 22. Çanak etrafındaki taşların planı (Davidson,1983).

\section{Sonuc}

Japonların, doğanın ahenkli olduğuna dair bir inançları vardır. Onlar, kendilerine bazen zarar veren ama diğer zamanlarda nimetler sunan doğaya karşı belli bir mesafede durmaları gerektiğine inanırlar. $\mathrm{Bu}$ durum, aslında Japonlar'ın diğer insanlar arasında kurdukları mesafe ile de ilintilidir. Japon bahçeleri, doğayı tüm özellikleriyle özümseyen ve onun gizemini felsefi bir anlatımla betimleyen bir tasarımı içermektedir. Japon bahçe sanatında mutlak bir realizm vardır. Japonlar ruhlarındaki duygu ve güzellikleri katarak doğayı bahçeye uyarlar. İşte Japon ruhunun gizemi de burada saklıdır. Dünyadaki bahçe kültürlerinin içinde en doğal ve bir o kadar gizemli olan Japon bahçeleri, kullanılan bahçe stilleri ve bahçe elemanlarının taşıdıkları anlamları ile ayrıcalıklı konumda yer almaktadırlar. Japon bahçesinin özümsenmesi için öğelerinin neleri sembolize ettikleri, genel karakteristikleri ve yorumlamaları hakkında bilgi sahibi olmak gerekir. Bu denli gizemli ve anlam yüklü bahçeleri anlamak prensiplerini doğru kavrayarak elde edilecektir. Bahçeler hangi stilde yapilırsa yapılsın, tasarımda kullanılan elemanlar, bahçede yaratılmak istenen ruhu bozmayacak şekilde itina ile yerleştirilmelidir. Japon bahçe tasarımları, tasarımcının, davranışını ve karakterini ortaya koyacağından, tasarımlar basit bir düzenleme olarak görülmemelidir. $\mathrm{Bu}$ nedenle yapılan çalışmaların, bahçeler hakkında bilgi ve birikime sahip kişiler tarafindan denetlenmesi gerekmektedir. Japon bahçeleri, doğayı tüm özellikleriyle simgeleyen ve onun gizemini felsefi bir anlatımla betimleyen tasarımı içerir. Gündelik varoluş ile daha derin düşüncelere dalmış bir dünya arasında bir geçiş yaratır. Japonlar için bahçe, tabiat ile insan arasındaki bağdır. Bu bakımdan bahçede kullanılan elemanlar insanı tabiata yaklaştırıcı araçlardır. Japon bahçeleri, insan eli değdirilerek yapılmalarına rağmen tabiatın kendisidir. Japon bahçeleri yalnızca bahçe değil, bir kültürdür. Geçmişle buluşma yeridir. Batıda akla ve yaratıcilığa konan sinırlar, Japon kültüründe kaldırılmakta ve duygu desteği ile akla adeta kanat takmaktadir (Kandil, 1989). Japon bahçeleri, Doğunun mistizmini doğanın sinırsızlığı ile birleştiren ve eşsiz bir ruhun 
izleridir. Dünyanın her yerinde taklit edilmelerinin ve günümüzde yapılan tasarımlara örnek teşkil etmesindeki en önemli kriter; kimlik ve kurgunun doğru kurulması ve yansımasıdır. Bir Japon bahçesi yaratmak ancak Japon ruhunu anlamakla mümkün olacaktır. Sonuçta küçük bir bahçeye gölleri, denizi, tepeleri, dağları, ormanları yerleștirmesini bilen ve oraya can veren derin duygular besleyen tek ruh, Japon ruhudur. Japon ruhunun gizemini bir çift dize ile ifade etmek yerinde olacaktır (Meriç,1984): "Güzeldeki çirkinliği görmeyen, Nasıl bilsin, çirkindeki güzelliği"

\section{Kaynaklar}

Akdoğan 1974. Bahçe ve Peyzaj Sanatı Tarihi. Ankara Üniversitesi Basımevi, 290 s, Ankara

Conder 1964. Landscape Gardening in Japan, Dover Publications, Inc. New York

Anonim 2003. The Helpful Gardener, Stone InTheJapaneseRockGarden.http://www.helpfulga rdener.com/japanese/2003/garden.erişim8.03.201 2.

Çakar 2013.Uzak Doğu Bahçe Sanatı http://www.yesildunya.net/forum/en-guzel-bahce ornekleri/681-japon-bahceleri-japon-bahcesanati.html Erişim 6.1.2015

Çınar ve Atakan 2008. "Minyatür Bir Dünya Zen Bahçeleri (Ryoan-Ji Örneği)", İ.Ü. Orman Fak..Turkish Journal Of Geriatrics, vol.1,41-51

Çınar ve Öznam 2010. Traces Of İnteratıon In Garden Cultures: Turkish And Japanese Gardens , The 1st İnternational Symposium on Environment And Foresty, Türkıye, 4-6 Kasım, vol.1, pp.993

Dawidson 1983. The Art of Zen Gardens, A Guide to Their Creation And Enjoyment, çeviri: Jeremy P.T. - New York. ISBN 0-87477-253-2.8.

Deitz,P, 2008. Plum Blossoms.The Third Friend of Winter, Site Lines A Journal Of Place, 4(1),pp.3-5

Du Cane, 1908. The Flowers and Gardens of Japan. Published by Adam -Charles Black, London

Demirbaş,1997. Tarihsel Japon BahçeleriÜlkemizdekiKullanılabilirliğininDeğerlendirilmes i, İTÜ Fen Bilimleri Ens.Yük. Lisans Tezi, İst.

Edlinger A., (2008). Japanese Example or the Art of Appropriation, Architecture and Identity, eds. Peter Herrle, Erik Wegerhoff, Technische Universität Berlin. Habitat Unit

Engel 1967 Japanese Gardens for Today.C. E. Tuttle Company.

Ergan,D.,2013. Japon Bahçeleri Japon Bahçe SanatınınTarihselGelişimi.http://www.avrupapark bahceler.com/index.php erişim: 3.1.2015
Frederic,L.,1972. Daily Life in Japan at the time of Samurai 1185-1603. Translated by Lowe,E., Asia Faik/are Studies, Vol. 33 1, p. 156.

Güvenç 1979, 'Buruk Acı/Hurma Tadı"Japon Sanatı. O.D.T.U. Mimarlık Fak. Dergisi Cilt 5, Sayı 2,s 227-268,Ankara

Güvenç,B,1995. Japon Kültürü (5.Baskı), Türkiye İş Bankası Kültür Yayınları,No: 213, Sosyal ve Felsefi Eserler Dizisi: 21, Ankara.

Hobson, J.2007 Niwaki Pruning, Training and Shaping Trees the Japanese Way. Timber Press, USA.

Kandil,1989. Dünya Mimarlığından. Japon mimarlı̆̆ı. Japon mimarlığına Nasıl Bakmalıyız? Mimarlık dergisi yıl 27 sayı 236 89/4,Ankara.

Keane 1996. Japanese Garden Design Photography by H.Ohashi, Rutland

Ketchell,R.2001,Japanese Garden in a Weekend, Octopus Publishing Group Ltd., London.

Keskin G. P. Seyrek 2008, Japon Estetiğinin 8 Belirtisi.http://v3.arkitera.com/h35521-japonestetiginin-8-belirtisi.html erişim 8.1.2015

Meriç 1984. Japonyada Sosyoloji.volume 21 İ.Ü. Sosyoloji Konferans 1 Dergisi 45-48,Istanbul Nitschke, G., 2003. Japanese Gardens Right Angle and Natural Form, Taschen GmbH, Köln

Shigemori, M.,1981. Kyoto Shi Ukyou Ku, Ryoan-ji Goryou no Shitamachi, Kyoto,Japan.

Se1ke,K. 1992, A Japanese Touch For Your Garden, Kodansaha International, Tokyo, Japan Simon,H.2014.http://www.pinterest.com/pin/747 4912948935934/Fence ideas. Erişim 9.11.2014

Slawson, D. 1991 Secret Teaching in the Art of Japanese Gardens, Kodansaha International, Tokyo

Masuno, S.2003. Inside Japanese Gardens, From Basics to Planning, Management and Improvement, The Commemorative Foundation for the Internaional Garden and Greenery Exposition, Osaka

PilevneliM., 2007. http://bahcevan.com/kutsal-agac-ginkgo-biloba erişim tarihi 8.1.2015

Özgen,Y,1988/2.Japon Bahçelerinde Bazı Tasarım Teknikleri, İ.Ü. Orman Fak. Dergisi,A,Cilt 38, İstanbul

Özgen,Y.1988.Japon Bahçelerinin Tarihsel Gelişimi, İ.Ü. Orman Fak Derg. B,Cilt 38,S: 4. İst.

URL1,2013http://www.zengarden.org/html/pa ge_obj_shakkei.htm erişim 5.4.2013

URL2.2015.http://www.modanium.com/ruyad a-kopru-gormek/ tarihi 9.10.2015

URL3,2013blomsterdalen.dkhttps://www.goo gle.com.tr/search?q=japanese \&biw $=1366 \& b i h=6$ $51 \&$ source $=$ Exotic Japanese Garden Design Ideas - FreshFurniture.Erişim 6.12.2014 
URL4,2015http://www.agaclar.net/forum/pey zaj-bahce-duzenleme/7775.htm Erişim.5.1.2015

Van Tonder, G.J.,Lyons, M.J. 2005. Visual Perception In Japanese Rock Garden Design. Axiomathes 15 pp.353-371

Var 2005. Japon Bahçe Sanat1, K.T.Ü Orman Fak. Peyzaj Mimarlığı Bölümü Basılmamış Ders Notları, Trabzon.

Xiaofeng, F., 2010. The Great Gardens of China: history, concepts, techniques, Monacelli Press, London.

Yoshikawa, I.,1996. Japanese Gardening In Small Spaces, Japan Pub. Trading Co.,Tokyo,Japan

Young, D,2005. The Art of the Japanese Gardens, Tuttle Pub., Tokyo, Japan 